\title{
Kesiapan guru sekolah reguler untuk implentasi pendidikan inklusif
}

\author{
Mumpuniarti, Prima Harsi Kantun Lestari \\ Jurusan Pendidikan Luar Biasa FIP UNY. Jalan Colombo No.1, Yogyakarta, 55281, Indonesia. \\ *Corresponding Author. E-mail: primaharsikls@gmail.com
}

\begin{abstract}
Abstrak: Penelitian ini bertujuan memotret kesiapan guru sekolah regular melaksanakan pendidikan inklusi. Metode penelitian dengan menggunakan daftar pertanyaan kepada responden guru setelah mengikuti pelatihan tentang implementasi inklusi. Responden guru terdiri dari guru tingkatan satuan taman kanak-kanak/TK; satuan Sekolah Dasar/SD; dan satuan Sekolah Menengah Pertama/SMP. Analisis data menggunakan kategorial jawaban dari responden. Hasil penelitian menunjukkan bahwa pendidikan inklusi ternyata di satuan sekolah taman kanakkanak/TK lebih siap, karena terdukung kompetensi pedagogi. Bagi guru sekolah regular yang belum siap untuk implementasi pendidikan inklusi berharap adanya guru pendidikan khusus dan sarana akomodasi yang lengkap untuk implementasi pendidikan inklusi.
\end{abstract}

Kata kunci: kesiapan guru regular, pendidikan inklusi

\section{Readiness of regular school teachers for inclusive education implementation}

\begin{abstract}
This study aims to portrait the readiness of regular school teachers to carry out inclusive education. Research method by using questionnaires to teacher respondents after participating in training on implementation of inclusion. Teacher respondents consist of teachers in kindergarten/kindergarten level; elementary school / elementary school unit; and junior high school /junior high school units. Data analysis uses categorical answers from respondents. The results showed that inclusive education turned out to be better prepared in kindergartens/kindergarten schools, because pedagogy's competence was supported. For regular school teachers who are not ready to implement inclusive education expect special education teachers and complete accommodation facilities for the implementation of inclusive education.
\end{abstract}

Keywords: regular teacher readiness, inclusive education

\section{PENDAHULUAN}

Pendidikan inklusif berkembang dalam rangka memenuhi hak azazi bagi semua perserta didik dari berbagai potensi, latar belakang social-ekonomi, latar belakang etnis dan budaya untuk mendapatkan pendidikan yang berkualitas. Paradigma pendidikan inklusif muncul ketika dunia pendidikan berhadapan pada peserta didik yang berkebutuhan khusus atau peserta didik disabilitas untuk belajar bersama-sama di sekolah regular dengan teman-teman yang dipandang normal atau ratarata (Dolgova, Kutepova, Kapitanets, Kryzhanovskaya, \& Melnik, 2017). Berhadapan dengan peserta didik berkebutuhan khusus mengahruskan guru memiliki kesiapan kompetensi dari aspek pedagogi, psikologi, dan social, termasuk kesiapan mampu mengetahui potensi peserta didik. Jadi kemampuan diagnostik dan asesmen terhadap peserta didik berkebutuhan khusus menjadi keharusan pihak guru dalam rangka kesiapan implemetasi pendidikan inklusi (Dolgova et al., 2017).

Kesiapan guru sekolah reguler dalam implementasi pendidikan inklusi antara lain di bidang kurikulum dan pembelajaran, termasuk sarana pendukung pembelajaran. Menghadapi siswa mengharuskan guru sekolah regular memiliki kesiapan mengakomodasi kebutuhan belajar beragam, khususnya fakta ketika berhadapan dengan peserta didik berkebutuhan khusus (Zulfija, Indira, \& Elmira, 2013) ((Myers, 2014). Kesiapan guru regular merupakan kunci keberhasilan pelaksanaan inklusi, termasuk kesiapan untuk mengenal personal, sosial, dan potensi peserta didik. Guru sekolah regular untuk siap pada aspek tersebut perlu memiliki kompetensi asesmen, menafsirkan hasil asesmen, selanjutnya merancang program belajar dengan pertimbangan kebutuhan peserta didik yang beragam. Termasuk kebutuhan belajar peserta didik berkebutuhan khusus, karena di antara 


\section{J PK (J urnal Pendidikan Khusus), 14 (2), 2018 - 58}

Mumpuniarti, Prima Harsi Kantun Lestari

keberagaman tersebut pasti ada yang beragam sangat signifikan. Keberagaman yang sifnifikan itu yang dijumpai sebagai peserta didik berkebutuhan khusus.(Kwon, Hong, \& Jeon, 2017) (Kauffman \& Hallahan, 2011).

Kesiapan guru dalam implementasi pendidikan inklusi disampaikan (Myers, 2014) meliputi: 1) persepsi tentang pengaruh inklusi terhadap strategi pembelajaran; 2) level penerimaan makna kesiapan untuk mengajar terhadap peserta didik disabilitas; 3) pengembangan kompetensi professional untuk pembelajaran bagi peserta didik yang disabilitas; serta 4) hubungan kolaboratif antara guru regular dan guru khusus. Aspek-aspek tersebut dimaknai tentang kesiapan dalam bidang kompetensi pedagogis, kompetensi professional, kompetensi kepribadian, dan kompetensi sosial. Kompentensi tersebut terutama peningkatan kompetensi kepribadian dan sosial dengan bentuk peningkatan sikap positip terhadap implementasi pendidikan inclusive (Lisa \& Mohaffyza, 2017). Sikap positip akan menerima dan mendukung terhadap pelatihan-pelatihan yang diberikan lembaga peningkatan profesi guru dalam rangka kesiapan implementasi pendidikan inklusi. (Hay, 2014). Menerima maksudnya guru belajar dengan seksama bentuk-bentuk khusus pembelajaran dalam implementasi pendidikan inklusif. Maksud mendukung maksudnya guru bersedia untuk melaksanakan implementasi inklusif. Bentuk kelemahan atau kendala professional akan selalu dicari solusi oleh guru dengan mengikuti pelatihan untuk kesiapan implementasi inklusif (Hussin \& Hamdan, 2016).

\section{METODE}

Metode penelitian menggunakan sejumlah daftar pertanyaan terbuka kepada responden guruguru di sekolah area kota Yogyakarta. Daftar pertanyaaan diberikan ketika mengikuti pelatihan tentang peningkatan guru dalam pendidikan inklusi yang diselenggarakan oleh Dinas Pendidikan Kota Yogyakarta di bulan Juni sampai dengan Agustus tahun 2018. Pertanyaan diberikan ketika selesai mengikuti satu materi tentang mengenal peserta didik berkebutuhan khusus dan kebutuhan belajar dari peserta didik berkebutuhan khusus.

Peserta diberikan daftar pertanyaan dengan tujuan; memotret sikap dan pengetahuan yang dimiliki guru setelah diberikan materi tentang mengenal peserta didik berkebutuhan khusus dan kebutuhan belajar dari peserta didik berkebutuhan khusus. Hasil dari potret sikap dan pengetahuan guru tersebut sebagai dasar fakta tentang kesiapan guru regular mengimplementasikan pendidikan inklusif. Responden berjumlah 110 orang, terdiri dari guru pra-sedolah, guru sekolah dasar, dan guru sekolah menengah pertama.

Analisis data dengan deskriptif kuantitatif sederhana berupa persentase dan grafik batang, disertai kategorial jenis-jenis jawaban dari pertanyaan yang diberikan kepada responden. Jenis jawaban meliputi cara mengenal jenis-jenis peserta didik berkebutuhan khusus, tindakan yang akan dilakukan jika menemui peserta didik berkebutuhan khusus, serta kategori pernyataan siap dan belum siap untuk implemetasi pendidikan inklusi. Kesiapan yang lebih krusial adalah mampu melaksanakan pembelajaran di sekolah inklusif

\section{HASIL DAN PEMBAHASAN}

\section{Hasil}

\section{Kesiapan mengenal peserta didik berkebutuhan khusus}

Guru-guru dalam kesiapan kompetensi mengenal peserta didik berkebutuhan khusus, sudah siap melakukan. Hal itu terbukti dari jawaban-jawabana sejumlah pertanyaan sudah dapat menjawab sebagai berikut.

1. Cara mengenal/mengidentifikasi anak yang termasuk hambatan belajar, guru perlu melakukan di antaranya: a. Mengidentifikasi, mengasesment, mendiskripsikan kebutuhan program untuk mengetahui hambatan belajar untuk mengoptimalkan potensi dan mengatasi perkembangan; $b$. Mengobservasi tingkah laku, kemampuan akademik dan non akademik

2. Cara mengenal/mengidentifikasi anak yang termasuk hambatan komunikasi, antara lain yang dilakukan oleh guru: a. Mengajak anak untuk berkomunikasi dan memperhatikan bagaimana anak tersebut berkomunikasi dengan orang lain, mengidentifikasi dan tindak lanjut terhadap kebutuhan anak tersebut; b. Melakukan obsercasi terhadap kemampuan social anak; serta Observasi kemampuan bicara, kosa kata, dan cara berbicara. 
3. Cara mengenal/mengidentifikasi anak yang termasuk hambatan perilaku, guru berencana melakukan: a. Mengasesment anak tentang perilaku yang dilakukan; b. Memandang kategori perilaku masih taraf adaptif stsu termasuk kategori problem perilaku; serta c. Observasi perilaku sehari-hari di sekolah

4. Cara mengenal/mengidentifikasi anak gited/talented guru berusaha: Mengamati kemampuan berpikirnya, kemampuan kecerdasa, umur, sikap akademisnya, kemampuan memimpin dan mempunyai rasa tanggung jawab yang besar.

Keterangan lebih lanjut, terdapat beberapa guru yang masih memiliki pandangan yang sempit terhadap keberagaman peserta didik di kelas dan cara menemukenalinya. Namun, sebagian besar guru memiliki pengetahuan dan kesadaran mengenai keberagaman peserta didik di kelas. Untuk mengenal/ mengidentifikasi keberagaman dan kebutuhan belajar setiap peserta didik di kelas, guru memahami bahwa perlu dilakukan beberapa tahapan. Tahapan kegiatan yang dilakukan adalah mulai dari observasi dan pengamatan secara langsung baik mengenai kemampuan komunikasi, sosial sampai perilaku sehari-hari di sekolah. Setelah dilakukan observasi dan pengamatan secara langsung, guru berupaya untuk mengidentifikasi setiap perilaku yang dilakukan dan yang muncul pada anak. Selain observasi mengenai kemampuan komunikasi, sosial maupun perilaku, guru juga melakukan observasi dan identifikasi terhadap kemampuan akademik siswa. Identifikasi kemampuan akademik sebagai penunjuk tentang siswa mengalami hambatan dalam belajar dan bentuk hambatan siswa dalam belajar. Setelah melakukan identifikasi dan asesmen, guru akan mengidentifikasi dan membuat kebutuhan program untuk anak.

Selanjutnya, hasil jawaban responden disajikan mengenai kesiapan sekolah untuk menghadapi keberagaman peserta didik di kelas pada jenjang Taman Kanak/TK, Sekolah Dasar/SD, dan Sekolah Menengah Pertama/SMP di Kota Yogyakarta. Berurut-turut disajikan dengan jumlah responden setiap jenjang secara deskrit menyatakan sebagai berikut.

Tabel 1. Kesiapan menghadapi keberagaman peserta didik di kelas

\begin{tabular}{ccrcc}
\hline Jenjang Satuan sekolah & \multicolumn{2}{c}{ Siap } & \multicolumn{2}{c}{ Belum siap } \\
\hline TK & 6 & $100 \%$ & - & - \\
SD & 54 & $85.70 \%$ & 9 & $14.30 \%$ \\
SMP & 54 & $88.50 \%$ & 7 & $11.50 \%$ \\
\hline
\end{tabular}

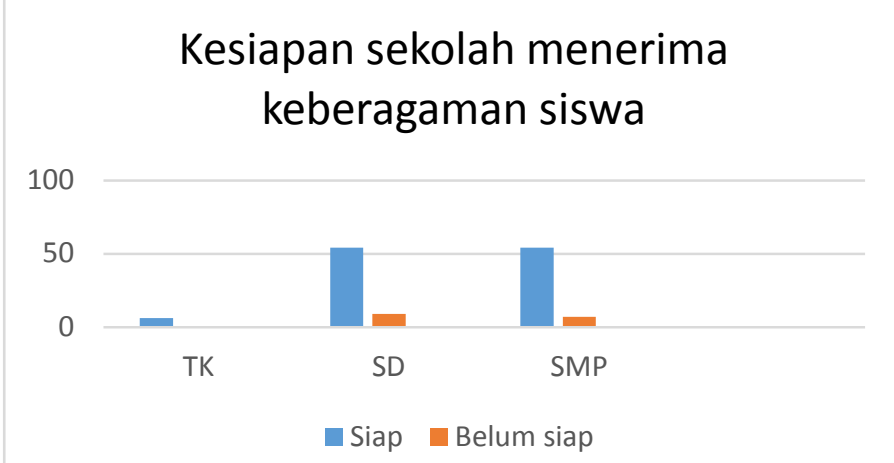

Grafik 1. Kesiapan sekolah dalam menerima keberagaman peserta didik di kelas

Berdasarkan tabel dan grafik tersebut dapat diketahui bahwa sekolah baik jenjang TK, SD dan SMP siap dalam menerima keberagaman peserta didik di kelas. Hal ini ditunjukkan dengan persentase kesiapan di tingkat TK 100\%, SD 85.7\% dan 88.5\% di jenjang SMP. Artinya, sebagian besar sekolah sudah siap menerima keberagaman peserta didik di dalam kelas.

1. Sudah siap. Yang perlu dipersiapkan

a. Sarana prasarana

b. Akomodasi

c. Pelatihan yang lebih intensif agar memiliki Sumber Daya Manusia/SDM yang mumpuni

d. Penyesuaian/adaptasi kurikulum 


\section{J PK (J urnal Pendidikan Khusus), 14 (2), 2018 - 60}

Mumpuniarti, Prima Harsi Kantun Lestari

2. Belum siap. Saran:

a. Mempersiapkan akomodasi pembelajaran yang lengkap

b. Perlu pelatihan agar guru memahami tentang ABK dan mampu memberikan layanan pendidikan yang layak dan sesuai.

c. Menyiapkan sarana dan prasarana

d. Perlu adanya guru pendamping.

Perspektif guru ketika dihadapkan pada keberagaman peserta didik di kelas, ternyata pada jenjang TK guru lebih tinggi sikap positif dan kesiapan menerimanya. Pada jenjang SD dan SMP masih terdapat sekolah yang merasa tidak siap dalam menerima keberagaman peserta didik di dalam kelas. Kenyataan tersebut menunjukkan bahwa di jenjang TK telah maju dalam hal kesadaran keberagaman peserta didik di dalam kelas. Keberagaman peserta didik di kelas harus dihadapi oleh guru dan pihak sekolah dangan perspektif yang benar.

Di tingkat SMP, sebagian besar guru memiliki pengalaman tentang keberagaman peserta didik dan pengalaman menghadapi peserta didik berkebutuhan khusus. Mereka mengambil tindakan yang dilakukan di kelas klasikal, guru cenderung hampir tidak dapat memperhatikan setiap siswanya. Terdapat guru yang terkesan “cuek” ketika menghadapi keberagaman peserta didik di kelas, ada yang memberikan perhatian khusus, namun ada pula yang merasa terbebani dan kerepotan dengan adanya keberagaman peserta didik di kelas. Guru merasa tidak mampu jika harus memberikan perhatian khusus terhadap satu siswa karena siswa yang lain akan terbengkalai.

Dalam menerima keberagaman peserta didik, terdapat banyak aspek dan banyak hal yang terlebih dulu harus disiapkan seperti sarana prasarana yang mendukung, kesiapan sumber daya manusia yang mumpuni, akomodasi yang memadai sampai kepada adaptasi kurikulum untuk keberagaman peserta didik di kelas. Adaptasi kurikulum melibatkan sekolah, guru maupun orang tua. Pandangan guru mengenai adaptasi kurikulum, guru dan sekolahan harus mengakomodasi sesuai kebutuhan belajar siswa. Sekolah dan guru harus berkolaborasi dan bekerjasama dengan pihak orang tua untuk menindaklanjuti hasil belajar anak.

\section{Pembahasan}

Temuan penelitian diperoleh bahwa guru-guru di tingkat satuan paling bawah, yaitu guru-guru di TK lebih peduli untuk menghadapi keberagaman peserta didik. Guru TK lebih siap untuk menghadapi peserta didik berkebutuhan khusus. Responden guru TK lebih sedikit jumlahnya, tetapi semuanya menyatakan siap melaksanakan inklusi. Kesiapan ditunjukkan telah mengenal asesmen, akomodasi pembelajaran, dan adaptasi kurikulum. Kesiapan guru TK tersebut menunjukkan kompetensi pedagogi lebih kuat, karena untuk guru TK lebih diutamakan kompetensi pedagogi (Kwon et al., 2017).

Kesiapan guru perlu akomodasi, sarana-prasarana, adaptasi kurikulum, dan pelatihan yang intensif. Hal itu menunjukkan bahwa guru lebih menguasai kesiapan melaksanakan pendidikan inklusi terletak pada kemampuan pembelajaran (Hay, 2014) (Hussin \& Hamdan, 2016). Untuk itu, kesiapan guru regular di sekolah inklusi Daerah Istimewa Yogyakarta perlu pelatihan tentang pembelajaran di kelas inklusif secara teknis (Kauffman \& Hallahan, 2011) (Zulfija et al., 2013).

Bagi guru yang belum siap melaksanakan inklusi lebih cenderung menyatakan perlu guru pendidikan reguler di sekolah regular dan sarana-prasarana akomodasi yang lengkap. Ketergantungan ini menunjukkan secara psikologis guru-guru belum dapat menerima keberadaan peserta didik berkebutuhan khusus di sekolah regular (Hay, 2014). Berbeda bagi yang sudah menerima peserta didik berkebutuhan khusus ingin berusaha mengikuti pelatihan tentang pembelajaran inklusi (Hussin \& Hamdan, 2016).

\section{PENUTUP}

Kesiapan guru sekolah regular di Daerah Istimewa Yogyakarta dalam implementasi pendidikan inklusi ternyata di satuan sekolah taman kanak-kanak/TK lebih siap. Hal itu dikarenakan kompetensi pedagogi guru sekolah TK lebih menonjol mendukung kompetensi implementasi pendidikan inklusi. Utama kesiapan implemetasi inklusi adalah menerima peserta didik berkebutuhan khusus dengan aneka kebutuhan belajar. Bagi guru yang belum siap lebih mengandalkan bantuan guru pendidikan khusus berada di sekolah regular dan sarana-prasarana akomodasi yang lengkap. 


\section{J PK (J urnal Pendidikan Khusus), 14 (2), 2018 - 61}

Mumpuniarti, Prima Harsi Kantun Lestari

\section{DAFTAR PUSTAKA}

Dolgova, V. I., Kutepova, N. G., Kapitanets, E. G., Kryzhanovskaya, N. V, \& Melnik, E. V. (2017). The study of motivational readiness of teachers to implement inclusive education of children with disabilities. Espacios, 38(40). Retrieved from https://www.scopus.com/inward/record.uri?eid=2-s2.085028593369\&partnerID=40\&md5=940f9d5b4ddb975c17cb235908795346

Hay, J. F. (2014). Teacher preparedness for inclusive education, (January 2001).

Hussin, M. K. A. Bin, \& Hamdan, A. R. Bin. (2016). Effect of knowledge, readiness and teaching technique in inclusive practices among mainstream teachers in Malaysia. International Journal of Early Childhood Special Education, 8(1), 1-15. https://doi.org/10.20489/intjecse.239573

Kauffman, J. M., \& Hallahan, D. P. (2011). Handbook of Special Education. Routledge, Taylor \& Francis Group. https://doi.org/10.1016/0270-3092(81)90032-1

Kwon, K.-A., Hong, S.-Y., \& Jeon, H.-J. (2017). Classroom readiness for successful inclusion: Teacher factors and preschool children's experience with and attitudes toward peers with disabilities. Journal of Research in Childhood Education, 31(3), 360-378. https://doi.org/10.1080/02568543.2017.1309480

Lisa, N., \& Mohaffyza, M. (2017). SOCIAL SCIENCES \& HUMANITIES Involvement of Mainstream Teachers in Inclusive Education : Are We Ready ?, 25, 205-214.

Myers, M. (2014). Students with disabilities: Perspectives of regular education teachers of increased inclusion. Dissertation Abstracts International Section A: Humanities and Social Sciences. Retrieved from http://search.proquest.com/docview/1627946613?accountid=14182\$\%5C\$nhttp://sfxhostedeu.e xlibrisgroup.com/44SUS/?url\%7B_\%7Dver=Z39.882004\%7B\&\%7Drft\%7B_\%7Dval\%7B_\%7Dfmt=info:ofi/fmt:kev:mtx:dissertation\%7B\&\%7Dg enre=dissertations+\%7B\&\%7D+theses\%7B \&\%7Dsid=Pro

Zulfija, M., Indira, O., \& Elmira, U. (2013). The Professional Competence of Teachers in Inclusive Education. Procedia - Social and Behavioral Sciences, 89, 549-554. https://doi.org/10.1016/j.sbspro.2013.08.892 